\title{
Hybrid Mesh Technique to Model a Deep Bar Induction Motor Using Time Stepping Finite Elements Analysis
}

\author{
Prof. Basil M Saied \\ Electrical Engineering department \\ University of Mosul \\ Basil-ms@hotmail.com
}

\author{
Ahmed J. Ali \\ Foundation of Technical Education \\ Technical College of Engineering/Mosul \\ ahmedjad2005@yahoo.com
}

\begin{abstract}
This paper presents a 2-D nonlinear transient analysis using Finite Elements Method (FEM) to model a three phase deep bar cage induction motor. Accurate representation for this type of machines has been obtained based on the proposed method. In this model, rotation of the motor has been taken into consideration via use a special algorithm for changing the connection between stator and rotor using the coupled equations. A new approach has been used to reduce the ripple torque produced due to coupled equation between stator and rotor. The produced ripple in rotor bar current also has been reduced, by using different types of element shape to mesh the air-gap and cores of induction motor. The FEM has been tested for wide range of working performance from starting to steady state conditions. To validate the proposed model, a comparison with practical results gives a good verification. The nonlinear properties of the core material have been taken into consideration.
\end{abstract}

Index Terms: 2-D nonlinear FEM, Induction Motor; Coupling Equations; Performance Parameters.

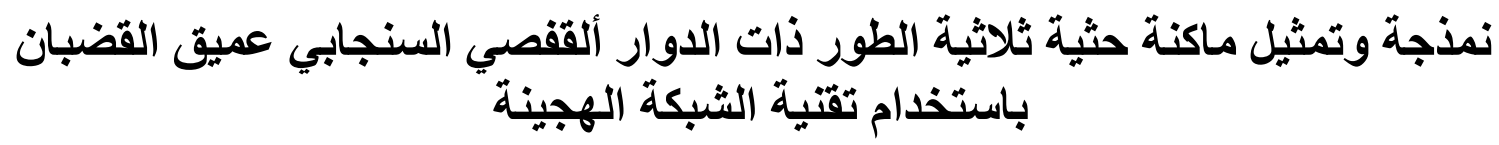

$$
\begin{aligned}
& \text { احمد جدعان علي العمان } \\
& \text { العراق/ الكلية التقتية / الموصل علي } \\
& \text { قسم القدرة الكهربائية }
\end{aligned}
$$

ahmedjad2005@yahoo.com

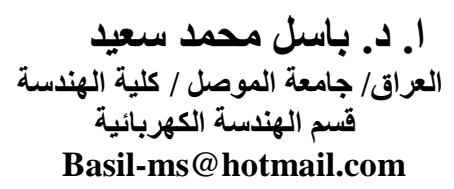

الخلاصة

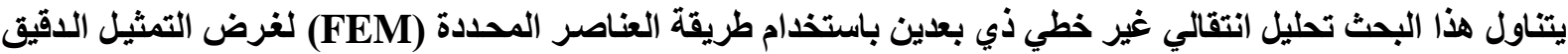

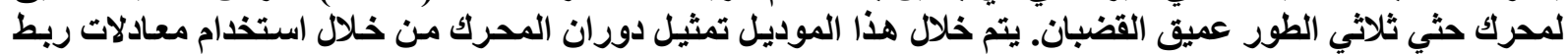

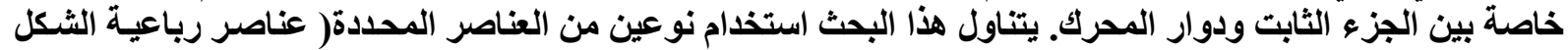

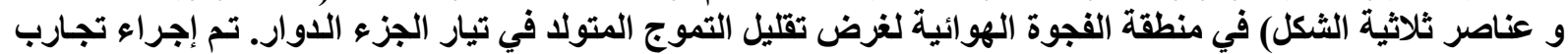

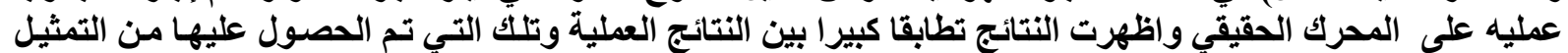

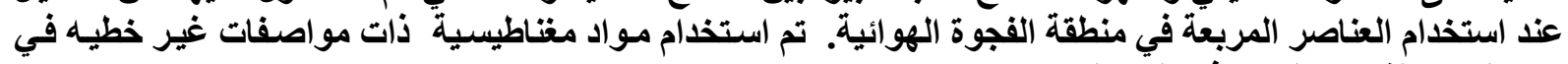
بناء الجزء الثابت والدوار في المحرك.
Accepted: 19 - 9 - 2012 


\section{Introduction}

The final stage before building the prototype of any electrical machine is to develop an accurate model which takes into consideration all the environments where the machine will work. The design of electrical machines requires an accurate and detailed calculation of it's parameters such as magnetic flux distribution, electromagnetic force, self and mutual inductance and developed torque. Different analytical methods had been used to simulate the induction machine, such as, winding function method (WFM) [1,2] and modified winding function method (MWFM) [3,4,5]. Both are based on linear assumptions for the variations of machine parameters. These methods have a simple representation of mathematical model, easy to implement and short simulation time.

But the obtained results have a wide range of approximations, due to the non-linear property of the machine, such as, saturation of magnetic flux density of magnetic core, skin effect through solid rotor bar and thermal varying of material properties. FEM is considered as the accurate approach that had been used to design and simulate the induction machine compared with WFM and MWFM [6]. The distribution of flux lines within the machine for non-linear core's material can produce an inductance which have a different value for the same machine with linear material property for both stator and rotor regions [7].

The FEM had been used to calculate the electromagnetic torque accurately compared with analytical methods. different methods had been used to calculate the torque using FEM, the Maxwell stress tensor, the virtual work method (co-energy method), the method proposed by Arkkio and the method of local Jacobian matrix derivation [8]. Maxwell stress tensor which has been considered in current work to calculate the torque is based on integrating the torque density over a specific surface. This surface is placed in the middle distance of the airgap and enclosing the rotor. The final value of the calculated torque depends on path of integral [9]. The second method is based on the partial derivative of the total energy or coenergy over the displacement of rotor. Selection a suitable step size of rotor displacement and the calculation of non-linear variation of total energy with respect to displacement are the two difficulties of this method [10].

Due to coupling equations between stator and rotor, the rotor bar currents and torque have a distorted signal shape. In the present paper in order to reduce the effects of this distortion, two types of elements shape have been used to mesh the model under simulation. The first type is the elements with rectangular shape to mesh the air-gap region, while the elements with triangular shape for the rest of motor regions. The proposed model has been compared with a model with rectangular elements for all it's parts. Keeping all elements types have the same element size in the air-gap region for both models. The dimension of all elements in the rotor bars is chosen to be less than the skin depth length. It has been found from simulation that the ripple is smaller, when the mesh of air-gap elements are rectangle compared with triangle assuming the same element size in both cases. This model may be used for different purposes such as, calculation of equivalent circuit parameters which is important for machine design, predicting many types of machine faults and to test the machine under design for different types of load conditions.

\section{Parameter Behavior of the Deep-Bar Machines}

Deep bar rotor induction machines had been designed for improving the starting performance of cylindrical cage-type. During starting, due to the skin effect phenomena, the 
rotor bar have a large a.c. resistance, and small inductance. The situation will be reversed at steady state speed. As the squirrel-cage bar is made very deep and narrow, the current will be constrained on the top of the bar at high slip frequency, increasing the effective resistance, while at full speed, when the slip frequency is low, the current will be more uniformly distributed, giving low resistance[11].

\section{Finite Element Model Apporach A. Modeling with Symmetry Usage}

Due to symmetry of the motor geometry, only one pole has been considered for representing the machine. This will reduce both, the effort of modeling and simulation time consumed during simulating the complete model without loss of accuracy. A 3-phase, 18,5 $\mathrm{Kw}$, star-connected induction motor has been used in present work. Using classic ANSYS software, the simulation results have been validated by comparing with the measured values for the motor. The local field quantities of the two-dimensional Finite Element algorithm has been coupled to electric circuits. The tested motor is shown in Fig.1.

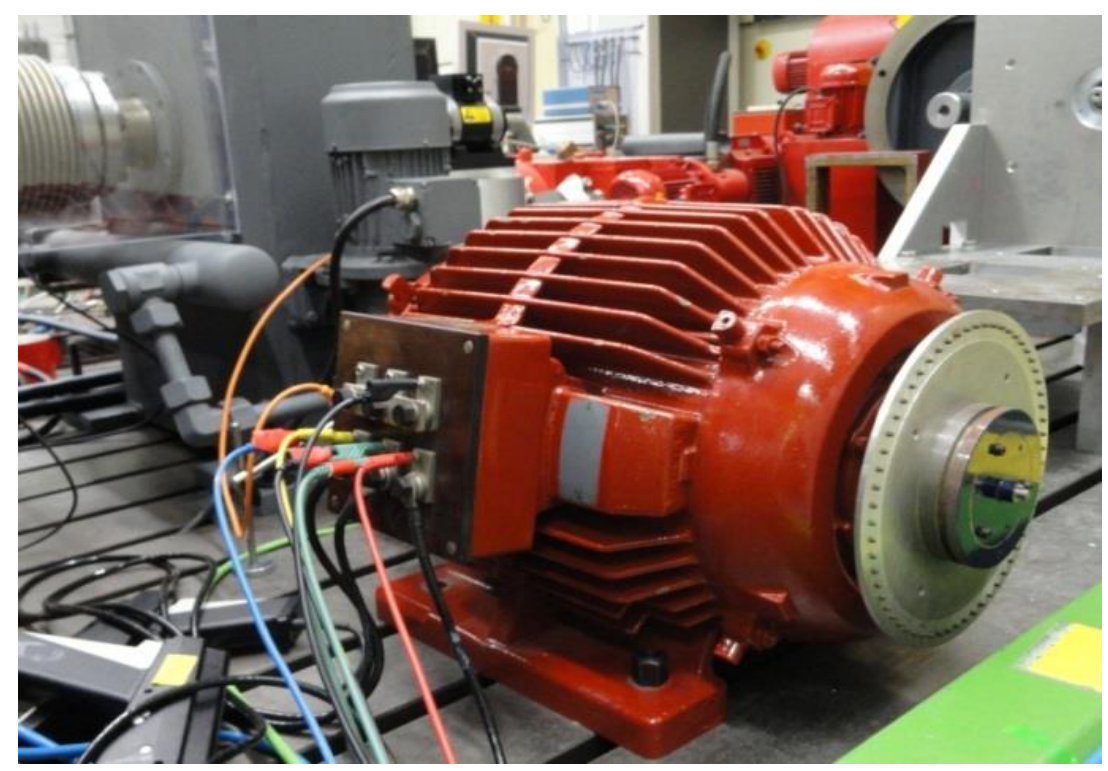

Fig. 1 Three phase squirrel cage induction motor used in the work

\section{B. The Mesh Model Type Effects}

Mesh of the model has a great effect on the simulation results, therefore the elements size should be selected carefully. The air-gap geometry will affect directly on the torque calculation, while the elements size of stator and rotor regions have an effect on flux density and eddy current on the two regions respectively. The air-gap region is divided into two zones; one of them is attached to the stator region and the other to the rotor region. The two air gap zones should have a rectangular mesh elements shapes and have the same number of mesh elements as shown in Fig. 2. 


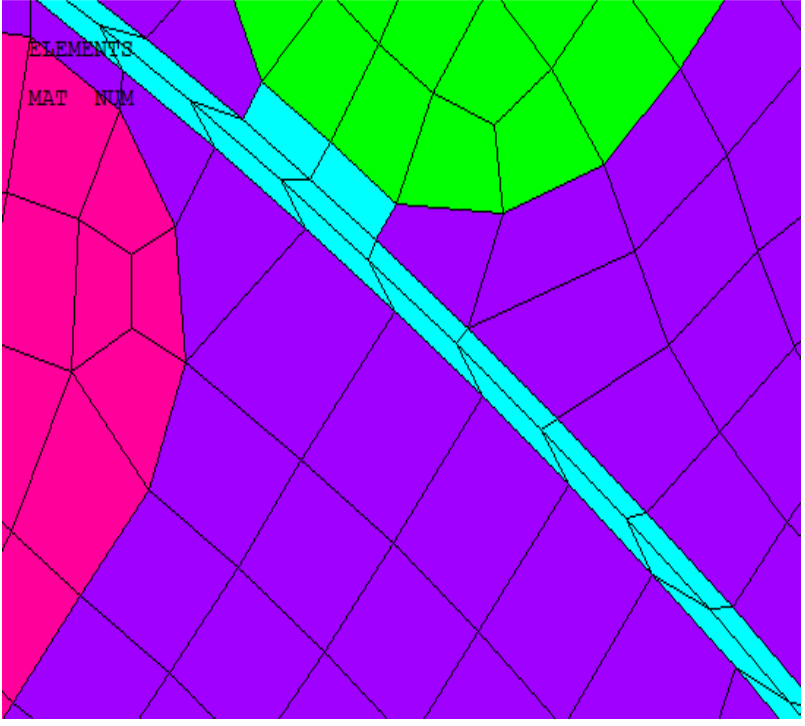

(a)

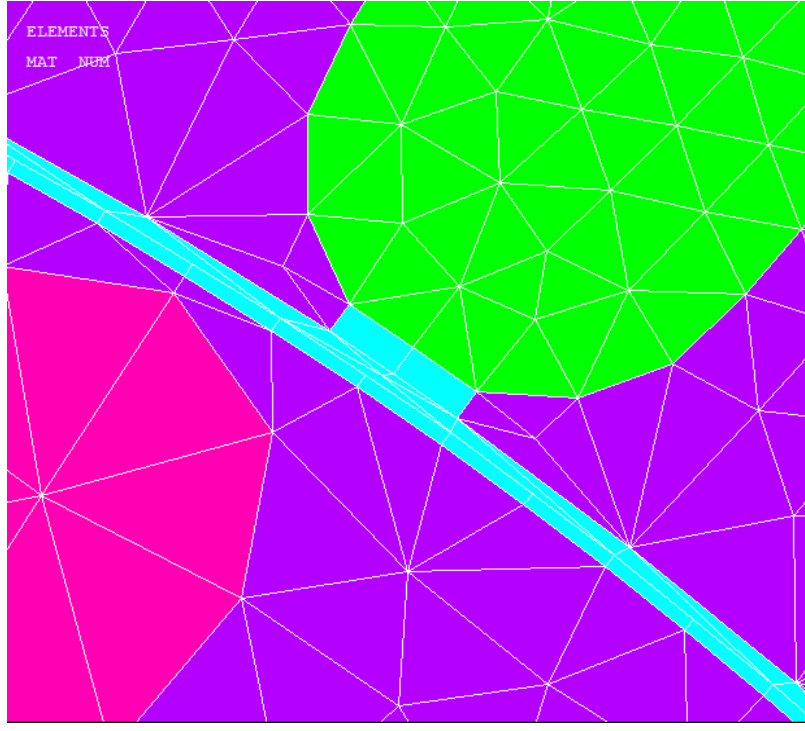

(b)

Fig. 2 Types of Mesh elements of a Three- phase squirrel cage induction motor used in the work. (a) Rectangular Mesh Element Type.

(b) Triangular Mesh Elements type.

The middle line of the air-gap should have the same number of coincide nodes for the coupling areas of stator and rotor during simulation, using a concentrate equation in order to simulate the accurate rotation of the rotor. These nodes will be used for calculating the magnetic flux density in $x-y$ plane in order to calculate the electromagnetic torque. The nodes at the two air-gap areas are joined together by using constraint equations to simulate the rotation of the motor [12].

\section{Fundamental Assumptions}

A 2-D FEM has been used to model the induction motor. The electromagnetic field have the following assumption :

- Due to low frequency power supply, it is assumed that the displacement current equal to zero.

- The magnetic vector potential and the current density have a component on $z$-direction. Therefore the governing equation of the electromagnetic field can be written in the following form [12]:

$\nabla \cdot\left(v \cdot \nabla A_{z}\right)-j w \sigma A_{z}=-J_{s}$

Where $v$ is the reluctivity of the magnetic material, $\mathbf{J}_{\mathrm{S}}$ is the applied current density over the stator windings, $\mathrm{w}$ is the source angular frequency and $\sigma$ is the conductivity of the material. The Eq. (1) can be rewritten by using the relative permeability $v_{\mathrm{r}}$ and the permeability of the free space $\mu_{\mathrm{o}}$, and it can be written in the following form:

$$
\begin{aligned}
& \nabla .\left(v_{r} . \nabla A_{z}\right)-j w \mu_{o} \sigma A_{z}=-\mu_{o} J_{s} \\
& \frac{\partial}{\partial x}\left(v_{r} \frac{\partial A_{z}}{\partial x}\right)+\frac{\partial}{\partial y}\left(v_{r} \frac{\partial A_{z}}{\partial y}\right)=-\mu_{o} J_{s}+j w \mu_{o} \sigma A_{z}
\end{aligned}
$$

Eq. (3) is applied on rotor bars region, for stator slot area where the eddy current may be neglected, Eq. (3) become: 


$$
\frac{\partial}{\partial x}\left(v_{r} \frac{\partial A_{z}}{\partial x}\right)+\frac{\partial}{\partial y}\left(v_{r} \frac{\partial A_{z}}{\partial y}\right)=-\mu_{o} J_{s}
$$

Since the model is supplied from a constant voltage source, therefore it is coupled with FEM. Then the mathematical equation of the supply voltage can be written in the following form [13].

$$
v_{s}=e_{s}+i_{s} R_{s}+L_{s} \frac{d i_{s}}{d t}
$$

Where $\mathrm{v}_{\mathrm{s}}$ is the stator supply voltage, $\mathrm{R}_{\mathrm{s}}, \mathrm{L}_{\mathrm{s}}$ are the stator end windings resistance and inductance respectively, and $i_{s}$ is the stator current, while $e_{s}$ is the induced emf at stator windings. In a similar manner, the rotor circuit can be represented by:

$i_{r}=\iint_{s}\left(\frac{e}{\rho l}-j \frac{w}{\rho} A_{z}\right) d s$

Where $\mathrm{i}_{\mathrm{r}}$ is the rotor bar current, $\mathrm{s}$ is cross section area of the bar, e is the induced emf of the rotor bar.

\section{Calculation Of Developed Torque}

The developed torque has been computed by means of Maxwell's stress tensor. Since a 2$\mathrm{D}$ model has been used, therefore Maxwell's stress tensor will be integrated along a line $1_{\mathrm{g}}$ in the middle of the air-gap, and then multiplying the result by the active length of the rotor and the number of pole pairs. Because of the numerical nature of the finite element method, the result may depend on both the position of the integrating line and the number of chosen nodes for the numerical integration. Therefore it is preferred to compute the average value of the torque over the entire air-gap surface $S_{g}$. Then the torque is [14]:

$T_{e}=\frac{l_{g}}{g \mu_{o}} P \int_{s_{g}} r B_{r} B_{t} \cdot d s$

Where

$l_{g}$ is stack length $(\mathrm{m})$.

$\mathrm{g}$ is the air-gap length $(\mathrm{m})$

$\mathrm{P}$ is the number of pole pairs.

$\mathrm{r}$ is the mean air-gap radius (m).

$\mathrm{B}_{\mathrm{r}}$ is the radial component of the flux density $\left(\mathrm{wb} / \mathrm{m}^{2}\right)$.

$\mathrm{B}_{\mathrm{t}}$ is the tangential component of the flux density $\left(\mathrm{wb} / \mathrm{m}^{2}\right)$.

\section{Simulation Results}

The tested motor shown in Fig. (1) has the parameters listed in table (1).

\begin{tabular}{|c|c|c|c|}
\hline Rated power & $18.5 \mathrm{kw}$ & Total Rotor bar no. & 28 \\
\hline Rated speed & $1460 \mathrm{rpm}$ & Stator outer diameter & $270 \mathrm{~mm}$ \\
\hline Line voltage & $220 \mathrm{~V} \Delta, 380 \mathrm{~V} \mathrm{Y}$ & Stator inner diameter & $178 \mathrm{~mm}$ \\
\hline Phase current & $63.2 \mathrm{~A} \Delta, 36.5 \mathrm{~A} \mathrm{Y}$ & Rotor outer diameter & $176.8 \mathrm{~mm}$ \\
\hline Power factor & 0.86 & Shaft diameter & $62 \mathrm{~mm}$ \\
\hline Frequency & $50 \mathrm{~Hz}$ & No. of turns & 14 turn/layer \\
\hline Total Stator slots no. & 36 & Stack length & $180 \mathrm{~mm}$ \\
\hline Full Load Torque & 100 N.m. & & \\
\hline
\end{tabular}

Table (1), The parameter specification of motor under study 
A 2-D time-stepping Finite Elements Analysis (TSFEA) of the induction motor has been simulated for two mesh element (triangular and rectangular) types using ANSYS software. The dynamic performance parameters of the model for the two types of meshes have been calculated and compared to explain the difference between the results obtained. Fig. 3. represents the motor speed at start up condition for two types of mesh elements. While fig. 4. gives the relation of developed torque with time at same condition for two types of meshes. While, Fig. 5. explains the three phase currents of the simulated model. The rotor bar currents for the two strategies which have been used in the present work are shown in Fig. 6. A comparison between practical and simulated results are given in Figs ( 7 and 8) respectively for steady-state conditions.

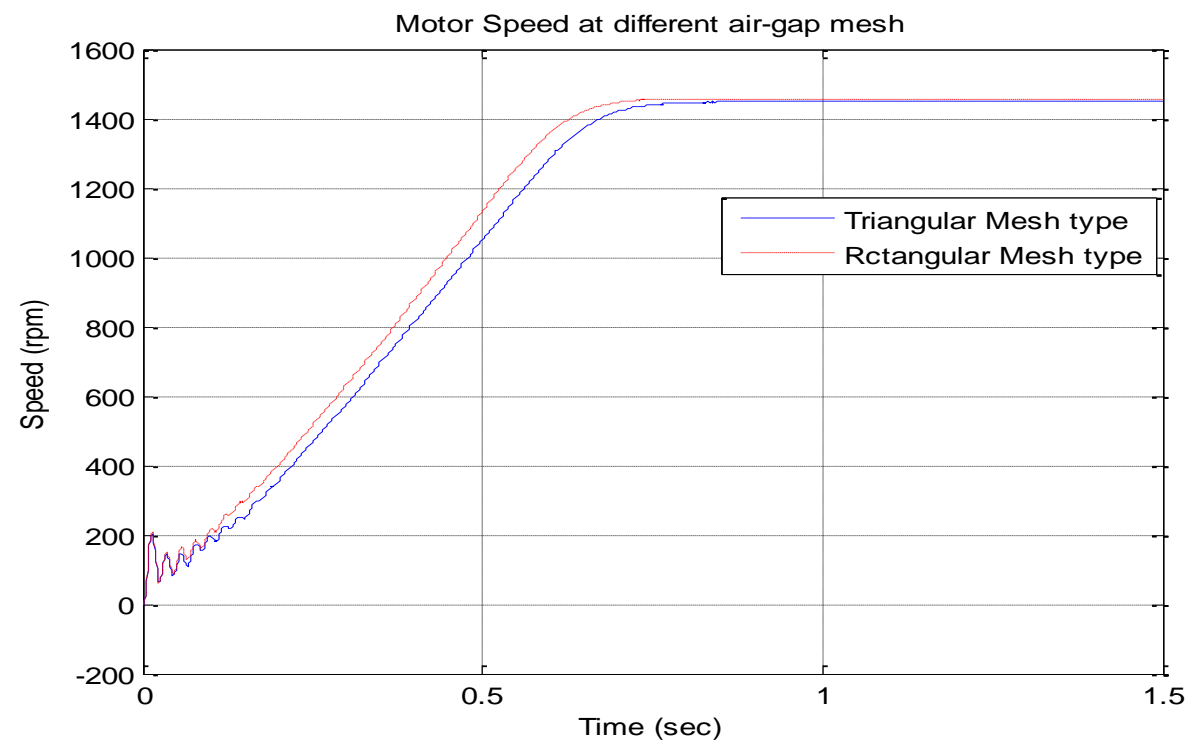

Fig. 3. speed-time relation at start up with full-load condition

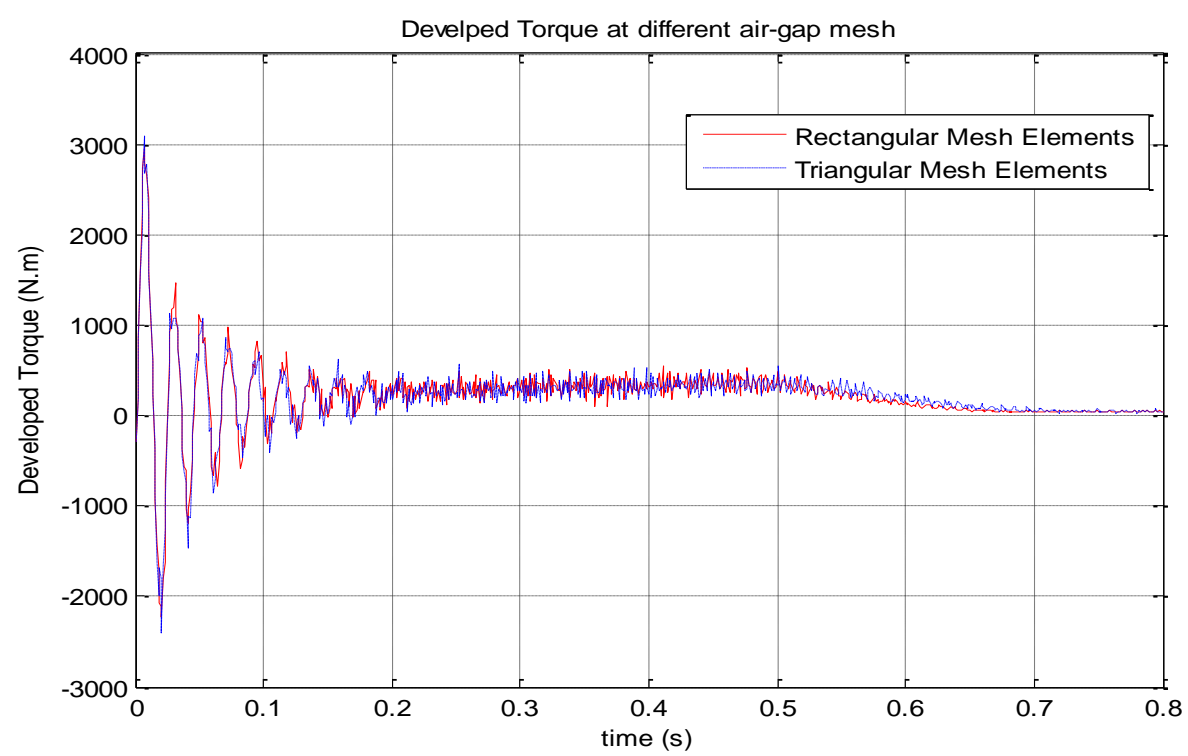

Fig. 4. Develop Torque-time relation at start up with full-load condition 


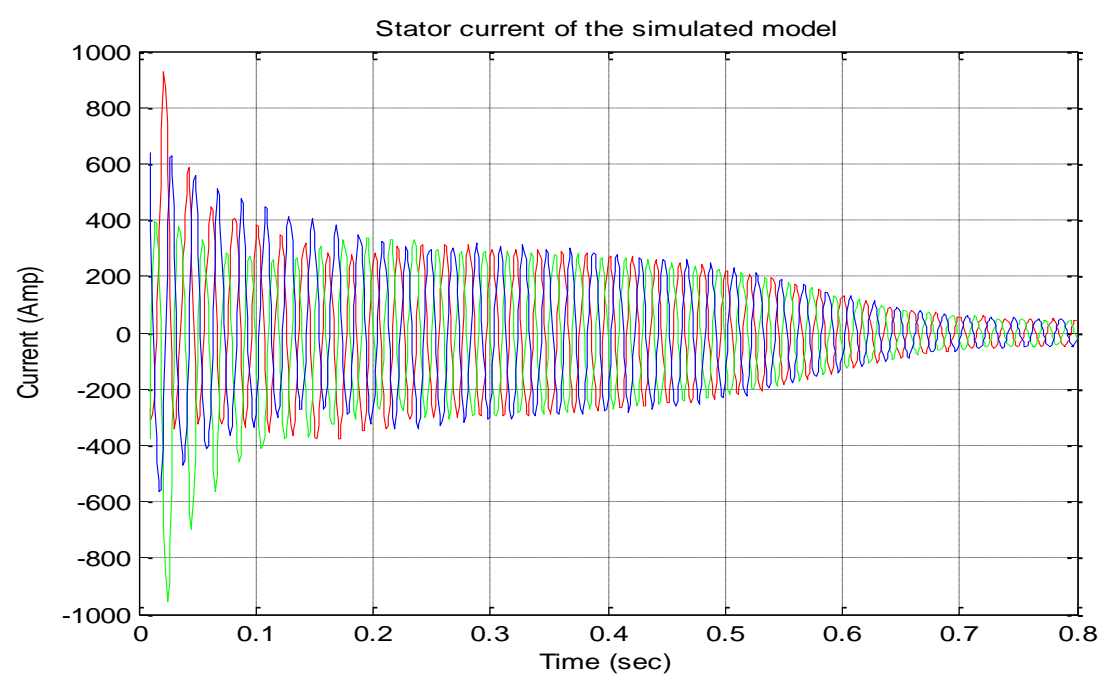

Fig. 5. Stator current with full load condition.

Due to low frequency of the bar cage rotor, the rotor currents have the waveforms shown in Fig. 7.

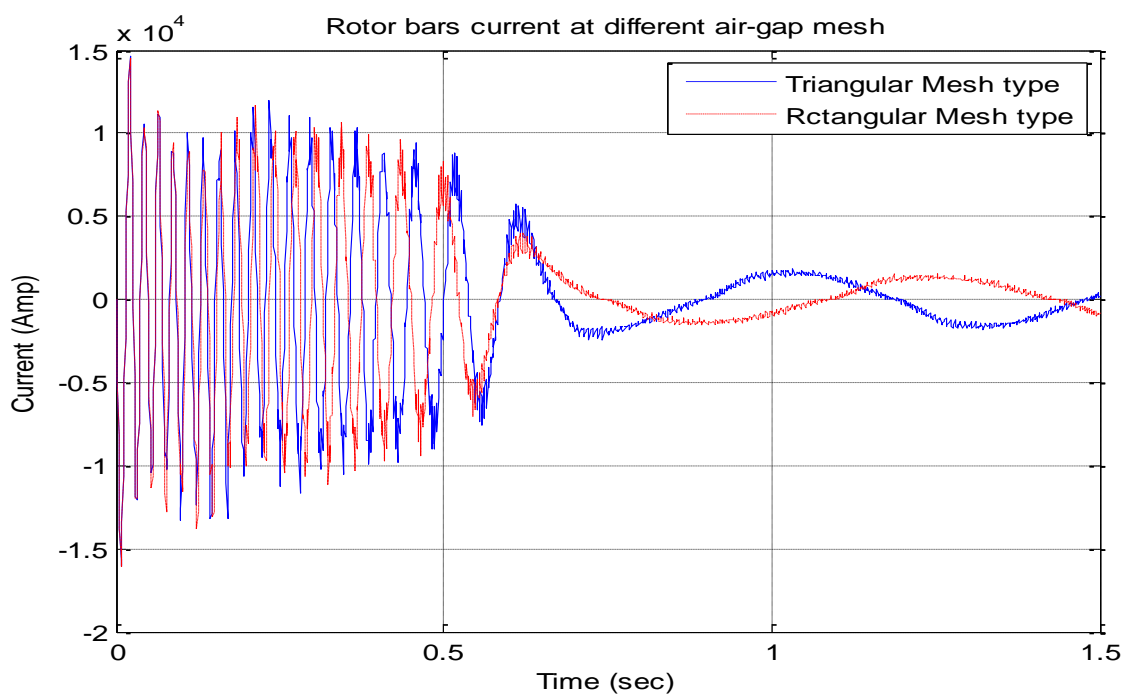

Fig. 6. The instantaneous rotor bar current with full load

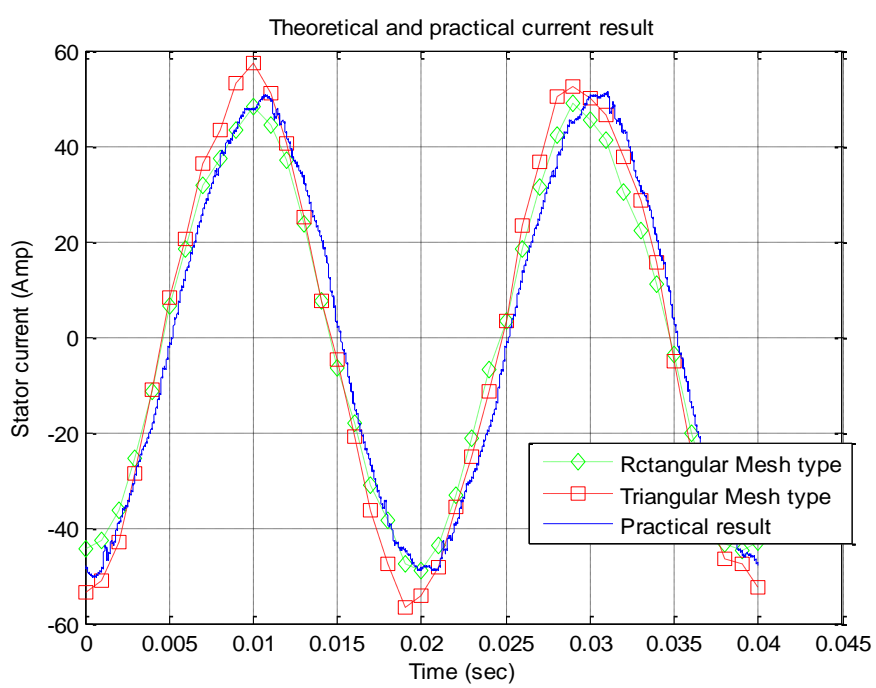

Fig. 7. The steady state instantaneous stator current at full load condition 


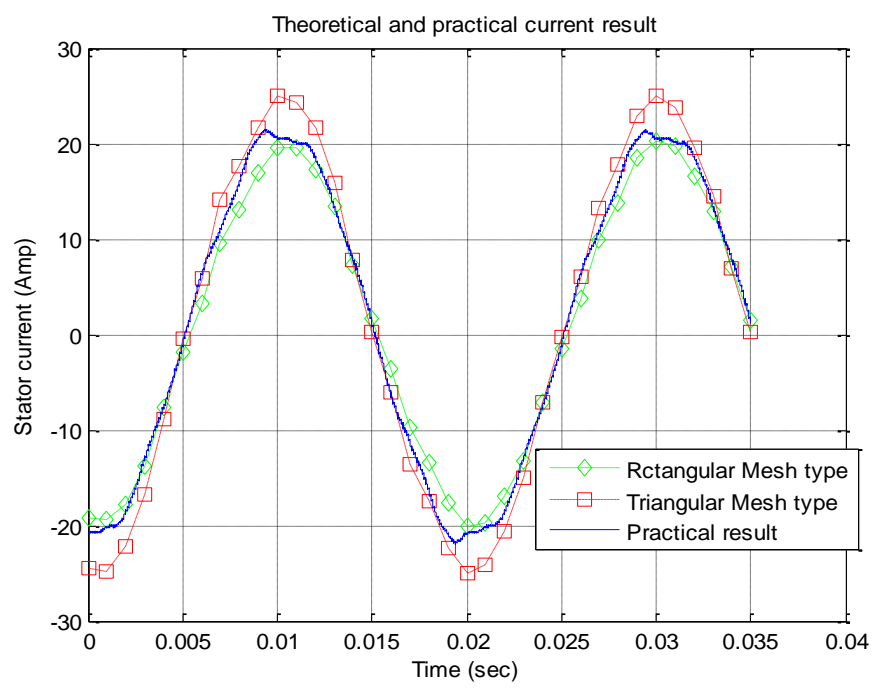

Fig. 8, The steady state instantaneous stator current at slight load condition

\section{Conclusion and Discussion}

A 2-D step by step finite element analysis has been used to simulate a three-phase induction motor in current work. Although this type of analysis require along simulation time, but it gives results have a good validity compared with practical results. Since the motor have odd periodically, therefore only pole has been considered which reduce the simulation time. Two types of mesh have been used in the simulation. From the results, it has been shown that the speed of the motor have a value greater than using of triangular mesh type elements on the air-gap region. The ripple values of the developed torque and rotor bars current display the same effect.

Table 2, Practical and simulated results at full load.

\begin{tabular}{|c|c|c|c|}
\hline & Triangular mesh & Rectangular mesh & Practical \\
\hline Motor speed (rpm) & 1448 & 1457 & 1459 \\
\hline Phase current(r.m.s) & 37 & 34 & 35 \\
\hline Develop torque (N.m) average & 125 & 110 & 102 \\
\hline
\end{tabular}

Table 3. Practical and simulated results at slight load.

\begin{tabular}{|c|c|c|c|}
\hline & Triangular mesh & Rectangular mesh & Practical \\
\hline Motor speed (rpm) & 1495 & 1486 & 1480 \\
\hline Phase current(r.m.s) & 17 & 15.2 & 16 \\
\hline Develop torque (N.m) average & 38 & 40 & 32 \\
\hline
\end{tabular}




\section{Reference}

1. Al-Nuaim N.A. and Toliyat H.A., "A novel method for modeling dynamic air-gap eccentricity in synchronous machines based on modified winding function theory", IEEE Transaction on Energy Conversion, vol. 13, N² 2, pp 156-162, June 1998.

2. M.G. Joksimovic, D.M. Durovic, J. Penman and N. Arthur, "Dynamic simulation of dynamic eccentricity in induction machines-Winding function approach," IEEE Trans. Energy Conversion, vol. 15, no. 2 , pp. 143-148, June 2000.

3. J. Faiz and I.T. Ardekanei, "Extension of winding function theory for nonuniform airgap in electric machinery," IEEE Trans. Magnetics, vol. 38, no. 6, pp. 3654-3657, Nov. 2002.

4. G. Bossio, C.D. Angelo, J. Solsona, G. García and MI. Valla, "A 2- D Model of the induction machine: Extension of the modified winding function approach," IEEE Trans. Energy Conversion, vol. 19, no. 1, pp. 144-150, Mar. 2004.

5. A. Ghoggal, M. Sahraoui, A. Aboubou, S.E. Zouzou and H. Razik, "An Improved Model of the Induction Machine Dedicated to Faults-Detection - Extension of the Modified Winding Function," In proceeding of IEEE ICIT 2005, Hong-Kong, China, 14-17 Dec. 2005.

6. Aileen,C.J. --- Nagarajan,S. Reddy,S.R. 'Detection of broken bars in three phase squirrel cage induction motor using finite element method ' International Conference on Emerging Trends in Electrical and Computer Technology Year: 2011 Pages: 249254 Provider: IEEE.

7. Kappatou, J.; Safacas, A.N. 'finite element inductance calculation in 3-phase squirrelcage induction machines with broken rotor bars', Power Electronics, Electrical Drives, Automation and Motion, 2006. SPEEDAM 2006. International Symposium on 23-26 May 2006, page(s): $1434-1437$.

8. Andrej Burakov and Prof. Antero Arkkio "Modelling The Unbalanced Magnetic Pull In Eccentric-Rotor Electrical Machines With Parallel Windings" Doctoral Dissertation, Helsinki University of Technology, Department of Electrical and Communications Engineering, Helsinki 2007.

9. Ali Ebadi, Mohammad Mirzaie and Sayyed Asghar Gholamian 'Employing Finite Element Method to Analyze Performance of Three-Phase Squirrel Cage Induction Motor under Voltage Harmonics ' , Research Journal of Applied Sciences, Engineering and Technology 3(10): 1209-1213, 2011 ISSN: 2040-7467, Maxwell Scientific Organization, 2011.

10. Antero Arkkio,"Synchronous torques of a cage induction motor from time-discretized finite element analysis", Electrical Machines and Systems (ICEMS), 2011 International Conference on 20-23 Aug.2011, page(s): 1 - 5 .

11. Hafiz, K. Nanda and G. Kar, N.C. 'Performance Analysis of Aluminum- and Copper Rotor Induction Generators Considering Skin and Thermal Effects ' IEEE Transactions on Industrial Electronics, 2010,Page(s):181-192 Hafiz Volume: 57 , Issue: 1.

12. M. H. Gmiden 1 and H. Trabelsi1 'Calculation of Two-Axis Induction Motor Model using Finite Elements with Coupled Circuit' IEEE Trans, 2009 6th International Multi-Conference on Systems, Signals and Devices, Page(s): $1-6$.

13. Pippuri, J. and Arkkio, A.'Time-Harmonic Induction-Machine Model Including Hysteresis and Eddy Currents in Steel Laminations 'Magnetic, IEEE Trans., July 2009.

14. Tong Yang, Libing Zhou, and Langru Li 'Parameters and Performance Calculation of Induction Motor by Nonlinear Circuit-Coupled Finite Element Analysis' IEEE Trans. Power Electronics and Drive Systems. PEDS 2009, page(s) 979-984.

The work was carried out at the college of Engineering. University of Mosul 